\title{
Morning handover
}

$\mathrm{M}$ orning handover: the passing of responsibility. Dr. Day said, "Alright. So, how did our patients do?"

Dr. Night said, "Ms. Teapot had a rough night. She saw the full moon and started to growl. I started her on a silver drip and her teeth retracted somewhat. She should probably see the dentist today. I also gave her a shot of garlic to prevent concurrent vampirism. We have to check her breath this morning, I gave her two hundred cloves because of her size and her family is visiting from California this afternoon."

"Sir Ernest's toes kept running away. We placed his feet in a net but they'd chew through lines. And we started catching dolphins as well, and between the toes getting out and the miserable dolphins getting tangled up, I decided to discontinue the net. I laid down some coral reefs instead and hopefully the toes will find some snugfitting anemones."

“Molly Mayfair's iambs did well. Scansion showed pentameter throughout most of the evening. I got called about a few verses of trochee but some Shakespearean sonnets reversed that. There was a question about her alliteration though. For about two hours, she was Holly Mayfair and then I got nervous when she became Jolly Mayfair. But this morning she's firmly and unarguably Molly Mayfair."

"We had one new admission, a 14thcentury gentleman, from a nautilus shell, with multiple flavouring issues. He has basil and oregano, both organic. Star anise three years ago on a trip to Kathmandu, for which he traded a bottle of vanilla extract. Black pepper, whole seeds. Cinnamon too, with some turmeric and cumin, causing a green curry on the odd numbered days of the month and a red curry on the even numbered days. There's a history of silphium too, which I didn't know people still

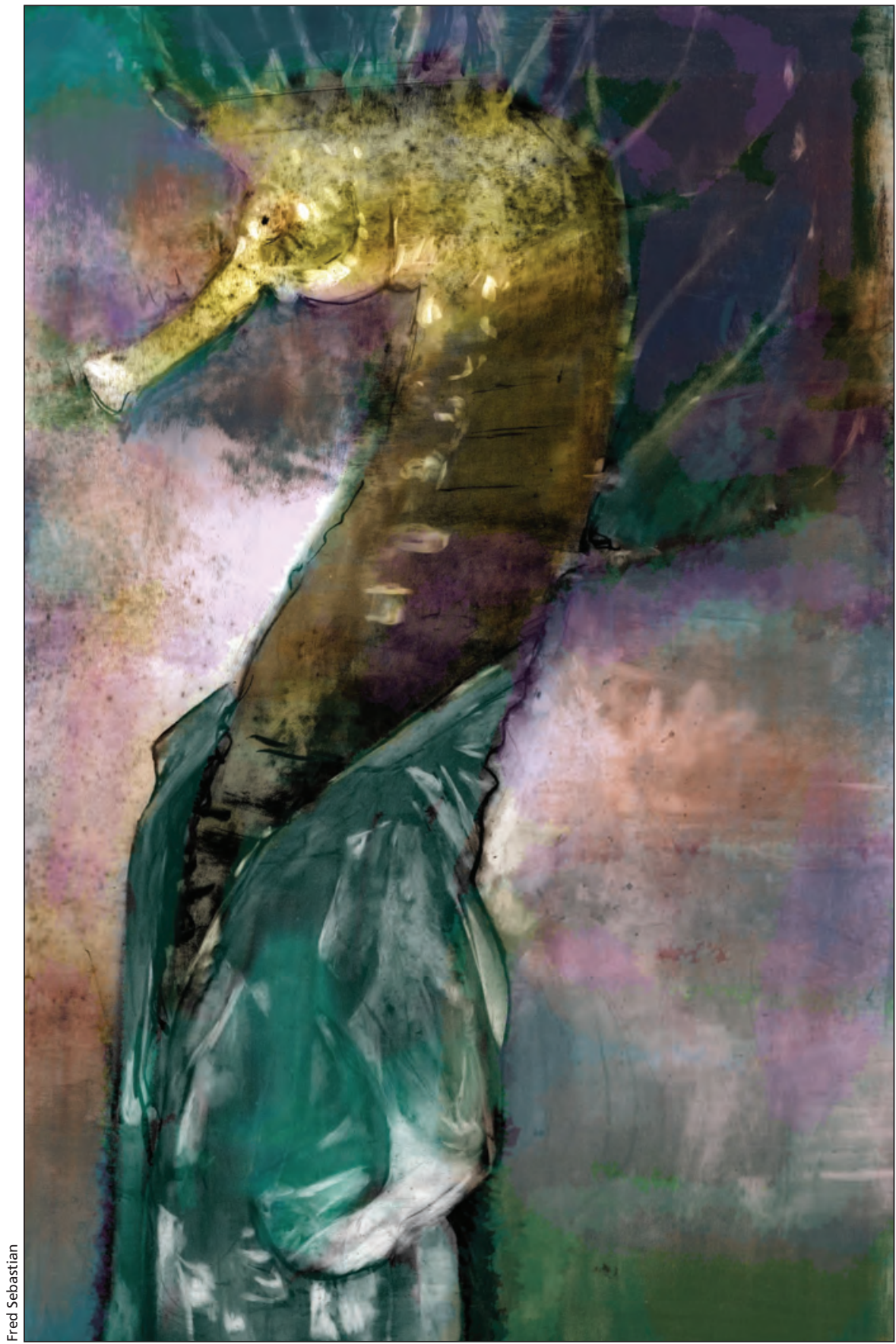

had. Now, he comes in with peaches and strawberries. Mostly freshly picked. Not associated with citrus, melons nor squashes. The juicing is fine, as is the peeling. We have some old jams that he made four years ago and they're still unspoilt. It's especially good if you eat them on the bread his uncle bakes. 
The peaches and strawberries from this season were pollinated by different bees though. He had switched apiarists and his new bees have a king instead of a queen. I did some reading and apparently that's the new trend in orchard management. The problem is that kings only move one square while queens can traverse the board. Kings do castle though, which is nice since he lives in an area with lots of hornets.

Otherwise, his meter is fine. He has twenty digits in ascending order. No signs of lycanthropy or phantasms. He's a seahorse though so we'll have to keep an eye on that.

I thought the peaches were worse than the strawberries so I divided by seven. The remainder was less than four in both cases so I left well enough alone. He could probably tolerate more aggressive math; his equations are linear and homogenous. I just wanted him to undergo a Fourier transformation first because of his unique mélange. But there were no integrals available after sunset, so he had to wait."

Dr. Day kneaded his sourdough and said, "What's the gentleman's name?"

"Horace Horace."

"I think I saw him last month at the Extra General. Did he have an iguana familiar?"

"He did! I was thinking about that because people in this county have herd animals; if not some sort of rodent. It's the local grasslands. I was wondering where he's from. Anyway, I left orders for a full-spectrum ultraviolet lamp at the bedside."

"When I saw Horace Horace, his iguana was in mid moult and this was affecting the flavouring target. Not common here but lizard familiars cause an entymologic shift toward chitin and shellac, which becomes more pronounced during moulting. I had to call herpetology in Kingsborough. Did you notice any difference between his tongue and the iguana's?"

"There wasn't any last night. I saw a prescription for urushiol in his compounding list but he wasn't applying it anymore."

"Fair enough. He's an interesting gentleman. Thank you. Are you coming to the festival this weekend?"

"Yes I am but the dog is performing so I'll only be eating potatoes. And Gillian is doing headstands so we'll see!"

"Ah yes, the terrible headstands. Joanna started that when we took away her cactus. Succulents!"

Then, Dr. Night folded up his map and compass, returned his pins and weights to their pouches and pushed off from the dock.

Philip Tsang MD

Family physician

Ottawa, Ont.

CMAJ 2013. DOI:10.1503/cmaj.130673

\section{Stitching the perfect stomach}

$\mathrm{H}$ appiness for Ottawa, Ontariobased artist Karina Bergmans is creating the perfect stomach or liver or pancreas or kidney.

Bergmans has, she jokes, an "obsession" with body parts, specifically oversized, three-dimensional organs, lovingly made of vinyl, velvet or whatever scraps can be found among her sewing supplies.

Despite having a psychology degree, Bergmans has not yet discerned the origins of this obsession for organs and her desire to make them visible. But clearly Bergmans's giant, sometimes diseased, organs help demystify the body, its ailments and the world of medicine. It is easy to picture Bergmans's hammocksized perfect stomach as a teaching tool for children or as whimsical art in a hospital. These organs are approachable, educational and lovable, even the damaged ones - including the ulcer in the perfectly rendered stomach.

Bergmans's body parts obsession was well on its way to full realization

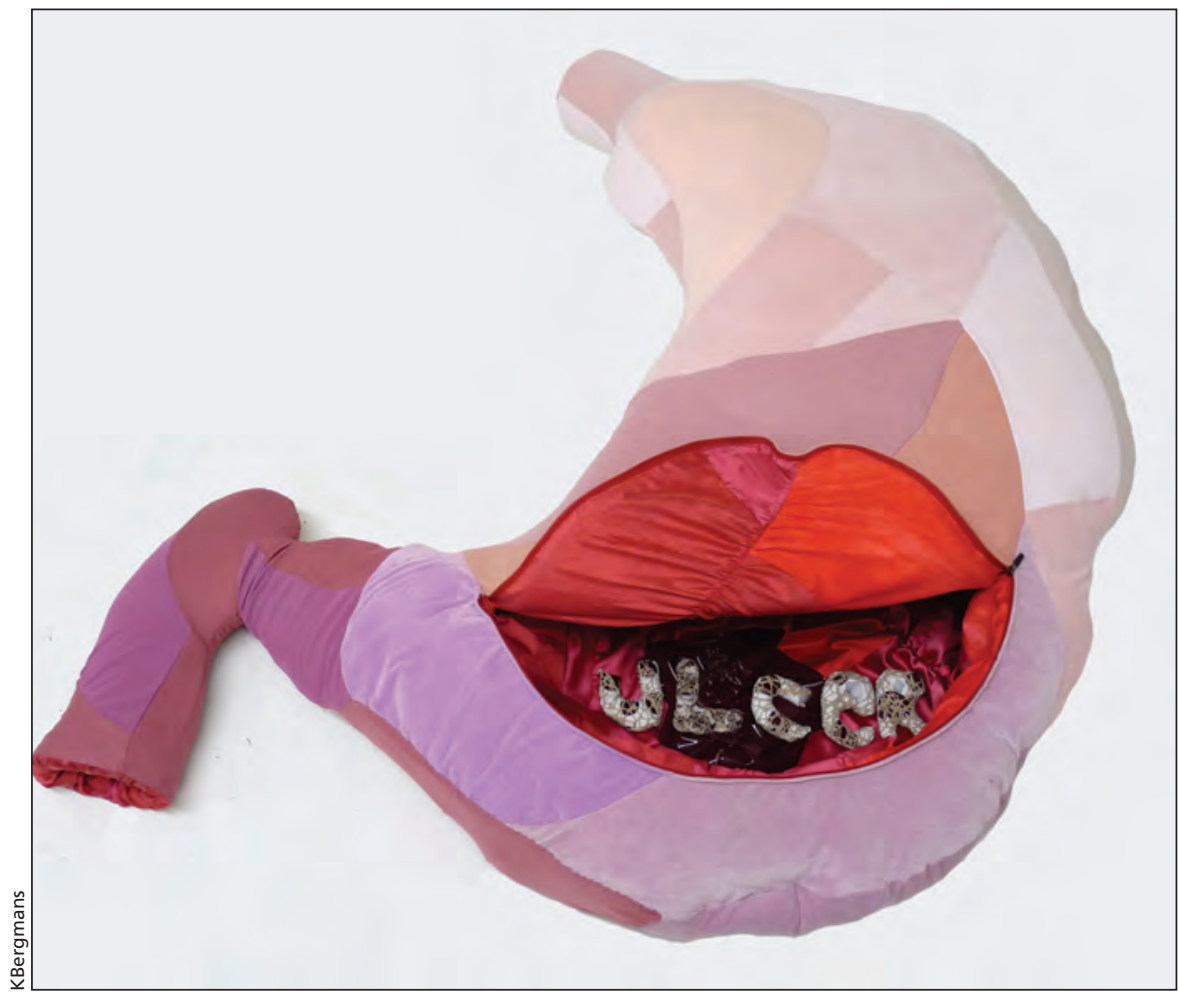

Stomachulcer, 2013, fabric, silk, foam, zipper, grommets, snaps. 